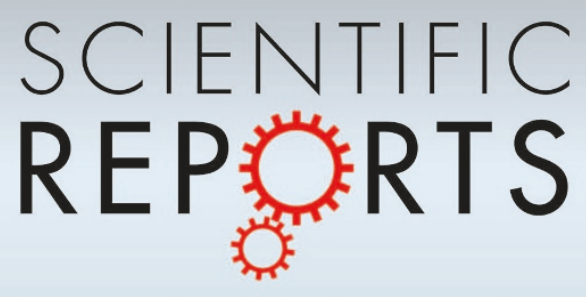

OPEN

SUBJECT AREAS:

CHEMICAL PHYSICS

NANOSCALE BIOPHYSICS

ENVIRONMENTAL CHEMISTRY

Received

2 December 2013

Accepted

6 May 2014

Published

23 May 2014

Correspondence and requests for materials should be addressed to H.L. (lihangswu@163.

com)

\title{
Strong non-classical induction forces in ion-surface interactions: General origin of Hofmeister effects
}

\author{
Xinmin Liu', Hang Li' ${ }^{1}$ Rui Li' ${ }^{1}$ Deti Xie' ${ }^{1}$ Jiupai Ni' \& Laosheng Wu²
}

\begin{abstract}
${ }^{1}$ Chongqing key laboratory of soil multi-scale interfacial process, College of Resources and Environment, Southwest University, Chongqing 400715, CHINA, ${ }^{2}$ Department of Environmental Sciences, University of California, Riverside, CA 92501, USA.
\end{abstract}

Hofmeister effects continue to defy all-encompassing theories, and their origin is still a matter of debate. We observed strong Hofmeister effects in $\mathrm{Ca}^{2+} / \mathrm{Na}^{+}$exchange on a permanently charged surface over a wide range of ionic strengths. They could not be attributed to dispersion forces, classical induction forces, ionic size, or hydration effects. We demonstrated that another stronger force was active in the ion-surface interactions, and which would create Hofmeister effects in general. The strength of this force was up to $10^{4}$ times that of the classical induction force, and could be comparable to the Coulomb force. Coulomb, dispersion and hydration effects appeared to be interwined to affect the force. The presence of the observed strong non-classical induction force implied that energies of non-valence electrons of ions/atoms at the interface might be heavily underestimated in current theories, and possibly just those underestimated energies of non-valence electrons determined Hofmeister effects.

$\mathrm{H}$ ofmeister effects, also known as specific ion effects, were observed over 120 years ago. Even though they are ubiquitous in the physical, chemical and biological literature, their origin is still contested ${ }^{1-7}$ and has been recently brought to the forefront of research ${ }^{8-19}$. New work in this area may break down barriers between physics and biology?.

Ionic sizes, hydration, quantum fluctuations (or dispersion forces) ${ }^{3,4,8}$, and surface charges ${ }^{1,2}$ are crucial in Hofmeister effects. Nano-scale surfaces and colloidal particles (e.g., DNA, proteins, cells, bacteria, metal oxides, and clay) are usually strongly charged in aqueous solution, and the sign of the charge or the charge number for biological macromolecules will be dependent on $\mathrm{pH}$ and ionic strength ${ }^{20}$. In classical theory, the surface charges can set up a strong electric field extending from the surface to several nanometers in solution. Typical surface charge densities and their corresponding electric field strengths include: (1) membrane with surface charge densities of $0.28 \mathrm{C} / \mathrm{m}^{2}{ }^{20}$, and electric fields of $4 \times 10^{8} \mathrm{~V} / \mathrm{m}$ (assuming a planar surface); (2) for natural clay (e.g., illite), it is $\sim 0.2895 \mathrm{C} / \mathrm{m}^{221}$, with an electric field of $\sim 4.2 \times 10^{8} \mathrm{~V} / \mathrm{m}$ at the surface; (3) for metal oxides it is $0.3-1.0 \mathrm{C} / \mathrm{m}^{22-25}$, with a surface electric field of $10^{8} \sim 10^{9} \mathrm{~V} / \mathrm{m} ;$ (4) for artificially synthesized nano- $\mathrm{TiO}_{2}$, it is $0.25 \mathrm{C} / \mathrm{m}^{2}$ and $3 \times 10^{8} \mathrm{~V} / \mathrm{m}$, respectivel ${ }^{26}$. For proteins, surface charge density measurements are primarily based on zeta potentials; therefore, they would be equal to the charge density at the shear plane, which is possibly much lower than the charge density at the surface ${ }^{27-29}$, especially when considering the strong surface hydration force ${ }^{30-32}$. At the shear plane, the charge density could reach $0.02-0.35 \mathrm{C} / \mathrm{m}^{233-35}$, with an electric field of $10^{7}-$ $10^{8} \mathrm{~V} / \mathrm{m}$. Therefore, it is reasonable to expect electric field strengths $>10^{8} \mathrm{~V} / \mathrm{m}$ at protein surfaces in aqueous solutions. However, in those calculations, adsorbed counter-ions near the surface are treated as point charges. If their ionic size were taken into account, then the electric field near the surface would be much greater than $10^{8} \mathrm{~V} /$ $\mathrm{m}$. This is because the finite size of counter ions could weaken their screening effect, as compared with point charges.

Noah-Vanhoucke and Geissler found that, the persistence of electric field in the space near liquid-vapor interface shapes the sensitivity of solute distributions to ion polarizability, and the electric field often plays central role in the influence of ionic polarizability on ion density profiles ${ }^{36}$. Surely, the distribution of the polarized ions would reversely influence the electric field itself. Therefore, at the interface, ionic polarization, ionic distribution and the electric field are interwined. At the solid/liquid interface, however, we often meet strong electric field greater than $10^{8} \mathrm{~V} / \mathrm{m}$, the effects observed by Noah-Vanhoucke and Geissler might be much stronger and much more complex. 
In classical theory, induction forces are much weaker than dispersion forces; thus the contribution of induction forces to Hofmeister effects can be neglected. In strong electric fields of $10^{8}-10^{9} \mathrm{~V} / \mathrm{m}$, however, we must question the validity of classic induction theory for three reasons. First, if an atom or ion is strongly polarized, the binding force of the nucleus to the extranuclear electrons decreases, and, simultaneously, the contribution of the high external electric field to the energy of the electrons is greatly enhanced. The exact additional potential energy of the electrons from the high external electric field should be included in the Hamilton operator. Second, the range of electrostatic forces from surface charges is longer than that from a single ion ${ }^{20}$, which means that at the surface the additional force on an ion/atom from the external electric field and polarization effects will be long range. Third, there are many counter-ions around the surface and if they are all strongly polarized in the high external electric field ${ }^{37,38}$, then they will reversibly and strongly influence the external electric field itself. All of these effects must be correctly evaluated.

Because the selectivity coefficient in cation exchange equilibrium varies exponentially with cation-surface interaction energies for the two cation species involved, a slight difference in their respective interaction energies could result in significant differences in selectivity coefficient. Therefore, the ion selectivity coefficient is a useful parameter in quantitative evaluation of Hofmeister effects. For quantitatively evaluate the Hofmeister effects, we should firstly evaluate the contribution of Coulomb interaction to the selectivity coefficient accurately. We recently derived exact analytic solutions for the nonlinear Poisson-Boltzmann equation for cation exchange in mixed electrolyte solutions ${ }^{39}$. This enables accurate evaluations of Coulomb interaction effects on the selectivity coefficient, which in turn allows experimental evaluation of Hofmeister effects on the selectivity coefficient from cation exchange equilibrium data. As a result, a comparison can be made between experimental results and calculated Hofmeister effects that take into account ionic size, hydration, dispersion forces, and classical induction forces.

By analyzing published $\mathrm{Ca}^{2+} / \mathrm{Na}^{+}$exchange equilibrium data under a wide range of electrolyte concentrations and ionic strengths $\left(0.00075-0.354 \mathrm{~mol} / \mathrm{l}^{21}\right)$, we found that the observed Hofmeister effects could not be understood in terms of any classical interaction effects noted above, but instead requires a strong new force between cation and surface.

\section{Results}

Selectivity coefficient of cation exchange by classical Coulomb force. For $\mathrm{Ca}^{2+} / \mathrm{Na}^{+}$exchange, the selectivity coefficient may be defined as:

$$
K=\frac{a_{N a} N_{C a}}{a_{C a} N_{N a}}
$$

where $a_{\mathrm{Na}}$ and $a_{\mathrm{Ca}}$ are the activities of $\mathrm{Na}^{+}$and $\mathrm{Ca}^{2+}$, respectively, in bulk solution (mol/l), and $N_{\mathrm{Na}}$ and $N_{\mathrm{Ca}}$ are the adsorbed quantities (mmol/g) of $\mathrm{Na}^{+}$and $\mathrm{Ca}^{2+}$, respectively, because of the Coulomb force.

An advantage of Eq. 1 is that it can quantitatively evaluate the relative preference between $\mathrm{Ca}^{2+}$ and $\mathrm{Na}^{+}$. Thus, when $K>1$, there is a preference of $\mathrm{Ca}^{2+}$ over $\mathrm{Na}^{+}$in exchange; and vice versa for $K<1$.

If cation adsorption forces were Coulomb, Eq. 1 gives $^{40}$ :

$$
K_{\mathrm{C}}=\frac{a_{N a} \int_{0}^{\frac{1}{\kappa}} S c_{C a}(x) d x}{a_{C a} \int_{0}^{\frac{1}{\kappa}} S c_{N a}(x) d x}=\frac{\int_{0}^{\frac{1}{\kappa}} e^{-\frac{Z_{C a} F \varphi(x)}{R T}} d x}{\int_{0}^{\frac{1}{\kappa}} e^{-\frac{Z_{N a} F \varphi(x)}{R T}} d x}
$$

where $K_{\mathrm{C}}$ is the selectivity coefficient determined by the Coulomb forces for $\mathrm{Ca}^{2+}$ and $\mathrm{Na}^{+}$in cation-surface interactions; $R$ is the gas constant $(\mathrm{J} / \mathrm{mol} \cdot \mathrm{K}) ; T$ is temperature $(\mathrm{K}), F$ is the Faraday constant, $Z$ is the charge number of cation species; $\varphi(x)$ is the potential at position $x$ in the diffuse layer; $S$ is the specific surface area; $c_{i}(x)$ is the concentration of the $i$ th cation species at $x$; and $1 / \kappa$ is the effective thickness of the diffuse layer (or Debye length).

Liu et al. obtained the exact analytical solution of the non-linear Poission-Boltzmann equation for $2: 1$ and $1: 1$ mixed electrolyte solutions ${ }^{39}$. From the analytical solution of $\varphi(x)$, we can get the following simple relationships under relatively high surface potential conditions $\left(\sum_{i}\left|Z_{i} \varphi_{0}\right|>0.1 \mathrm{~V}\right)$ :

$$
\int_{0}^{\frac{1}{\kappa}} e^{-\frac{z_{C a} F \varphi(x)}{R T}} d x=\sqrt{3+c_{N a}^{0} / c_{C a}^{0}} e^{-\frac{z_{C a} F \varphi_{0}}{2 R T}}
$$

and

$$
\int_{0}^{\frac{1}{\kappa}} e^{-\frac{Z_{N a} F \varphi(x)}{R T}} d x=\sqrt{3+c_{N a}^{0} / c_{C a}^{0}} e^{-\frac{Z_{N a} F \varphi_{0}}{2 R T}}
$$

Thus Eq. 2 yields:

$$
K_{\mathrm{C}}=e^{-\frac{z_{C a} F \varphi_{0}-Z_{N a} F \varphi_{0}}{2 R T}}
$$

Taking $x=1 / \kappa$ to be the upper limit of the integrations in Eq. 2 (meaning $\varphi_{1 / \kappa} \rightarrow 0$ ), we thus have $Z_{i} F \varphi_{0}=Z_{i} F \kappa\left[\varphi_{0}-\varphi_{1 / \kappa}\right](1 / \kappa)=$ $-Z_{i} F \bar{E}(1 / \kappa)=\bar{w}_{i(\mathrm{C})}$, where $\bar{E}=-\kappa\left[\varphi_{0}-\varphi_{1 / \kappa}\right]$ is the mean electric field strength in the diffuse layer, and $\bar{w}_{i(\mathrm{C})}$ is the mean Coulomb potential energy of the $i$ th cation species in the diffuse layer. Thus Eq. 3 can be expressed as:

$$
K_{\mathrm{C}}=e^{-\frac{\bar{w}_{C a(\mathrm{C})}-\bar{w}_{N a(\mathrm{C})}}{2 R T}}
$$

According to Eq. 5, it was the mean potential energies of cation species in the diffuse layer that determine the selectivity coefficient $K$.

Strong Hofmeister effects in $\mathrm{Ca}^{2+} / \mathrm{Na}^{+}$exchange. If we consider Bolt's $s^{21}$ experimental results for $\mathrm{Ca}^{2+} / \mathrm{Na}^{+}$-illite exchange equilibria in a solution of $\mathrm{NaCl}$ and $\mathrm{CaCl}_{2}$, there are four relevant aspects: (1) the $\mathrm{Ca}^{2+} / \mathrm{Na}^{+}$exchange was determined under a wide range of electrolyte concentrations and ionic strengths (0.00075-0.354 mol/ 1); (2) illite particle surfaces can be considered planer; (3) illite surface charges are constant and therefore the surface charge density is independent of $\mathrm{pH}$ and ionic strength; (4) the ionic radii of $\mathrm{Ca}^{2+}$ $(0.099 \mathrm{~nm})$ and $\mathrm{Na}^{+}(0.095 \mathrm{~nm})$ are almost the same, but the hydration diameter of $\mathrm{Ca}^{2+}(0.52 \mathrm{~nm})$ is much larger than that of $\mathrm{Na}^{+}(0.356 \mathrm{~nm})^{41}$.

Bolt independently determined the surface charge density of illite $\left(0.2895 \mathrm{C} / \mathrm{m}^{2}\right)$ by the negative adsorption method ${ }^{21}$. With the Poisson-Boltzmann equation of the mean force, the surface potentials can be estimated from the classical $\sigma_{0} \sim \varphi_{0}$ relationship, where $\sigma_{0}$ is surface charge density $\left(\mathrm{C} / \mathrm{m}^{2}\right)$, and $\varphi_{0}$ is surface potential $(\mathrm{V})$. The results were shown in Table 1 . We note that ionic interaction energies in bulk solution would influence the distribution of cations in the diffuse double layer; therefore, we used activity instead of concentration for cation species in bulk solution, by using the modified Debye-Hückel equation ${ }^{42}$.

Using the data in Table $1, K_{\mathrm{E}}=a_{\mathrm{Na}} N_{\mathrm{Ca}} / a_{\mathrm{Ca}} N_{\mathrm{Na}}$ ( $K_{\mathrm{E}}$ is the experimentally determined $K$ ) and $K_{\mathrm{C}}$ (Eq. 5) values could be calculated. The values of $\varphi_{0}$ in Table 1 indicated that the condition $\sum_{i}\left|Z_{i} \varphi_{0}\right|>0.1 \mathrm{~V}$ was satisfied for all $K_{\mathrm{C}}$ calculations. In Figure 1 , it could be seen that the $K_{\mathrm{E}}$ were higher than the $K_{\mathrm{C}}$, and the difference increased with surface potential. The difference clearly revealed Hofmeister effects and implied that there are additional adsorption forces other than Coulomb for cation adsorption in $\mathrm{Ca}^{2+} / \mathrm{Na}^{+}$ exchange. Thus there are strong Hofmeister effects present in $\mathrm{Ca}^{2+} / \mathrm{Na}^{+}$exchange, which are strengthened by the increasing surface potential of illite particles.

Strong Hofmeister effects in $\mathrm{Ca}^{2+} / \mathrm{Na}^{+}$exchange based on classical interaction forces. The effect of dispersion forces. Equation 5 shows 
Table 1 | Surface potentials of illite particles for each exchange equilibrium ${ }^{21}$ (In the calculation of surface potential, the dielectric constant of water is $8.9 \times 10^{-9} \mathrm{C}^{2} / \mathrm{Jm}$ )

Concentration

$\left(\times 10^{3} \mathrm{~mol} / \mathrm{l}\right) \quad$ Activity $\left(\times 10^{3} \mathrm{~mol} / \mathrm{l}\right)$

Adsorbed (mmol/g)

\begin{tabular}{|c|c|c|c|c|c|c|c|c|}
\hline$c_{N a}$ & $c_{C a}$ & $a_{N a}$ & $a_{C a}$ & $\sqrt{I}\left(\times 10^{3} \mathrm{~mol} / \mathrm{l}\right)$ & $a_{N a} / a_{C a}$ & $N_{N a}$ & $N_{C a}$ & $\varphi_{0}(\mathrm{~V})$ (classical) \\
\hline 0.7 & 0.2 & 0.672 & 0.17 & 36.05 & 3.955 & 0.0054 & 0.111 & -0.1520 \\
\hline 1 & 0.2 & 0.956 & 0.167 & 40 & 5.724 & 0.01 & 0.105 & -0.1522 \\
\hline 3.2 & 0.15 & 2.993 & 0.115 & 60.41 & 26.06 & 0.029 & 0.0985 & -0.1565 \\
\hline 3.2 & 0.56 & 2.964 & 0.412 & 69.85 & 7.188 & 0.012 & 0.1005 & -0.1404 \\
\hline 5.1 & 0.2 & 4.697 & 0.144 & 75.49 & 32.63 & 0.034 & 0.091 & -0.1533 \\
\hline 6 & 1.3 & 5.396 & 0.851 & 99.49 & 6.344 & 0.015 & 0.104 & -0.1310 \\
\hline 9 & 2.3 & 7.893 & 1.361 & 126.1 & 5.800 & 0.019 & 0.1 & -0.1249 \\
\hline 29 & 0.8 & 24.31 & 0.395 & 177.2 & 61.54 & 0.077 & 0.07 & -0.1382 \\
\hline 19 & 9 & 15.45 & 3.933 & 214.5 & 3.928 & 0.019 & 0.0985 & -0.1112 \\
\hline 56 & 2.9 & 44.15 & 1.121 & 254.4 & 39.39 & 0.082 & 0.066 & -0.1245 \\
\hline 78 & 0.17 & 60.35 & 0.061 & 280.2 & 990.5 & 0.169 & 0.0195 & -0.1468 \\
\hline 95 & 6.8 & 70.57 & 2.071 & 339.7 & 34.07 & 0.084 & 0.064 & -0.1161 \\
\hline 34 & 29.4 & 25.1 & 8.729 & 349.6 & 2.875 & 0.018 & 0.101 & -0.1009 \\
\hline 138 & 0.5 & 100.3 & 0.14 & 373.5 & 718.0 & 0.176 & 0.0175 & -0.1347 \\
\hline 170 & 0.79 & 120.5 & 0.2 & 415.2 & 603.6 & 0.175 & 0.0185 & -0.1301 \\
\hline 238 & 1.1 & 161.8 & 0.235 & 491.2 & 688.9 & 0.17 & 0.017 & -0.1243 \\
\hline 65 & 138 & 40.25 & 20.28 & 692.1 & 1.984 & 0.018 & 0.103 & -0.09010 \\
\hline 296 & 103 & 177.2 & 13.24 & 777.8 & 13.38 & 0.085 & 0.0705 & -0.09245 \\
\hline
\end{tabular}

that selectivity coefficient $K$ is a function of mean potential energy of cation species in the diffuse layer. If dispersion forces were present, Eq. 5 becomes:

$$
K_{\mathrm{C}+\mathrm{D}}=e^{-\frac{\left[\bar{w}_{C a(\mathrm{C})}+\bar{w}_{C a(\mathrm{D})}\right]-\left[\bar{w}_{N a(\mathrm{C})}+\bar{w}_{N a(\mathrm{D})}\right]}{2 R T}}
$$

where $\bar{w}_{i(\mathrm{D})}$ was the mean dispersion energy of cation species $i$ in the diffuse layer; the selectivity coefficient $K_{\mathrm{C}+\mathrm{D}}$ is determined by both Coulomb and dispersion forces.

Considering $\bar{w}_{i(D)}$ is constant (independent from surface potential) ${ }^{3}$, and if the differences between $K_{\mathrm{C}}$ and $K_{\mathrm{E}}$ in Figure 1 come from dispersion forces, then $K_{\mathrm{C}+\mathrm{D}}=K_{\mathrm{E}}$. From Eqs. 1, 5 and 6, we obtain:

$$
\frac{K_{\mathrm{E}}}{K_{\mathrm{C}}}=\frac{K_{\mathrm{C}+\mathrm{D}}}{K_{\mathrm{C}}}=e^{-\frac{\bar{w}_{C a(\mathrm{D})}-\bar{w}_{N a}(\mathrm{D})}{2 R T}}=\operatorname{constant}(>1)
$$

Figure 2 plots $K_{\mathrm{E}} / K_{\mathrm{C}} v s$. $\varphi_{0}$, which is not constant. Therefore, the differences did not derive from the dispersion forces. The four red dots are $K_{\mathrm{E}} / K_{\mathrm{C}}$ values with very large values of $c^{0}{ }_{\mathrm{Na}} / c^{0} \mathrm{Ca}$ (red data in Table 1), and will be discussed below.

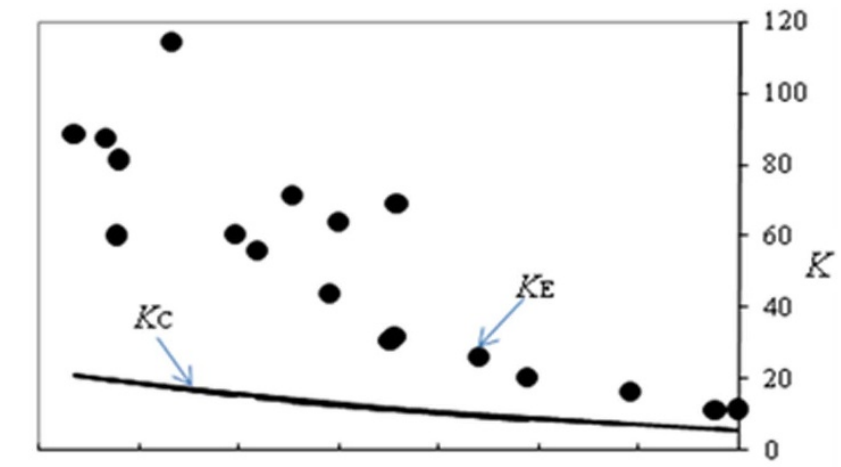

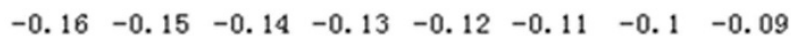

$\varphi_{0}$

Figure 1 Comparison between calculated (-) and experimental data (๑). $K_{\mathrm{E}}$ is the experimental selectivity coefficient; $K_{\mathrm{C}}$ is the calculated selectivity coefficient based on the classical theory.
Only under relatively high electrolyte concentrations is the dispersion force $e^{3,8,43-46}$ expected to become significant. Therefore, as the electrolyte concentration decreases, the difference between $K_{\mathrm{E}}$ and $K_{\mathrm{C}}$ decreases, and at very low electrolyte concentrations, $K_{\mathrm{E}} / K_{\mathrm{C}}$ will approach 1. However, Figure 2 showed that for decreasing electrolyte concentration (increasing surface potential), the difference between $K_{\mathrm{E}}$ and $K_{\mathrm{C}}$ increased. Therefore, we conclude that strong Hofmeister effects in $\mathrm{Ca}^{2+} / \mathrm{Na}^{+}$exchange did not derive from dispersion forces.

The same phenomena are also observed for enzyme activities in $<0.2 \mathrm{~mol} / \mathrm{L}$ solutions of $\mathrm{LiCl}, \mathrm{NaCl}$, and $\mathrm{CsCl}^{47}$, and for $\mathrm{K}^{+} / \mathrm{Na}^{+}, \mathrm{K}^{+} /$ $\mathrm{Li}^{+}, \mathrm{Na}^{+} / \mathrm{Li}^{+}$and $\mathrm{Mg}^{2+} / \mathrm{Na}^{+}$cation exchanges ${ }^{40}$.

The effects of ionic size and hydration. If the hydration effect became important in exchange, it would certainly decrease the preference of $\mathrm{Ca}^{2+}$ over $\mathrm{Na}^{+}$in the exchange since the hydration diameter for $\mathrm{Ca}^{2+}$ $(0.52 \mathrm{~nm})$ is much larger than that for $\mathrm{Na}^{+}(0.356 \mathrm{~nm})^{41}$, and then $K_{\mathrm{E}} / K_{\mathrm{C}}<1$. According to Yan Levin et al. ${ }^{1,2}$, the chaotropic $\mathrm{Na}^{+}$ cation would be more likely adsorbed at particle surfaces, whereas the kosmotropic $\mathrm{Ca}^{2+}$ cation would be more likely present in solution. This would decrease the preference of $\mathrm{Ca}^{2+}$ over $\mathrm{Na}^{+}$in the

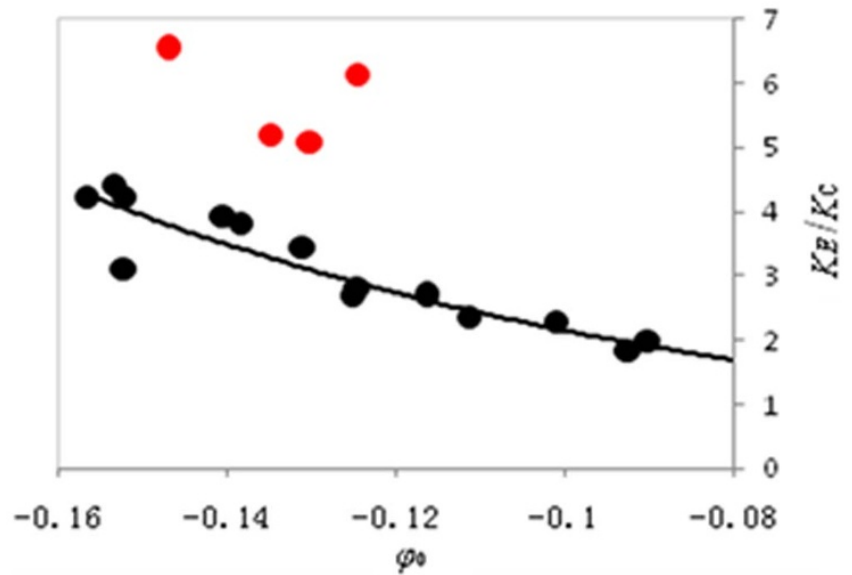

Figure $2 \mid K_{\mathrm{E}} / K_{\mathrm{C}}$ vs. $\varphi_{0}(\mathrm{~V})$ 


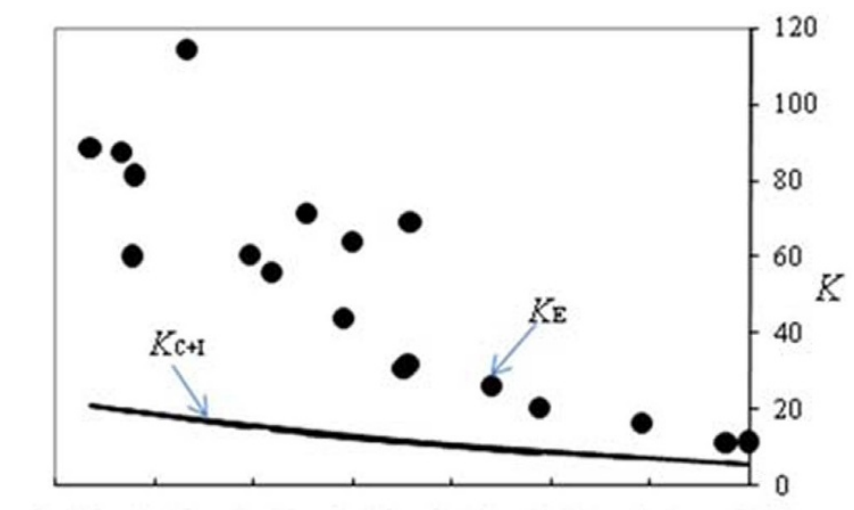

$\begin{array}{llllllll}-0.16 & -0.15 & -0.14 & -0.13 & -0.12 & -0.11 & -0.1 & -0.09\end{array}$

$\varphi_{0}$

Figure $3 \mid$ Comparison between theoretical curves of $K_{\mathrm{C}+\mathrm{I}}(-)$ and $K_{\mathrm{E}}$ (๑).

exchange because of the stronger dispersion and electrostatic forces per charge for $\mathrm{Na}^{+}$than that for $\mathrm{Ca}^{2+}$, and $K_{\mathrm{E}} / K_{\mathrm{C}}<1$. In Figure 2, however, $K_{\mathrm{E}} / K_{\mathrm{C}}>1$ and is not constant $v$ s. surface potential. Therefore, the hydration effect could not explain the $\mathrm{Ca}^{2+} / \mathrm{Na}^{+}$ exchange. One possible reason was that hydration and a hydration-dispersion combination ${ }^{2}$ may be correct only in relatively weak external electric field conditions of air/water and solid/liquid interfaces. In the dos Santo and Yan Levin study ${ }^{1}$, the surface charge density was merely $0.04-0.06 \mathrm{C} / \mathrm{m}^{2}$. Moreover, only under relatively high electrolyte concentrations would the ionic size (including hydration diameter) effect become significant ${ }^{48-58}$. Therefore, the difference between $K_{\mathrm{E}}$ and $K_{\mathrm{C}}$ should have decreased with electrolyte concentration, in contrast to Figure 1. Hence, the strong Hofmeister effects in $\mathrm{Ca}^{2+} / \mathrm{Na}^{+}$exchange did not come from differences in the ionic size, ionic hydration volume, or hydration-adjusted dispersion interactions between the ions and the surface ${ }^{1,2}$.

The effect of ionic induction force. Because increasing surface potential strengthened Hofmeister effects, they appear to be independent on dispersion forces, ionic sizes, and hydration effects. If it is the induction force in the electric field of the diffuse layer that was responsible for the large Hofmeister effects, then we have:

$$
K_{\mathrm{C}+\mathrm{I}}=e^{-\frac{\left[\bar{w}_{\mathrm{Ca}(\mathrm{C})}+\bar{w}_{\mathrm{Ca}(\mathrm{I})}\right]-\left[\bar{w}_{N a(\mathrm{C})}+\bar{w}_{\mathrm{Na}}\right]}{2 R T}}
$$

where $\bar{w}_{i(\mathrm{I})}$ is the mean induction energy of cation species $i$ in the diffuse layer.

Assuming that the dipole orientation near the particle surface is co-directional and parallel with the field direction, then the classical mean induction energy $(\mathrm{J} / \mathrm{mol})$ of $\mathrm{Ca}^{2+}\left(\bar{w}_{\mathrm{Ca}(\mathrm{I})}\right)$ and $\mathrm{Na}^{+}\left(\bar{w}_{\mathrm{Na}(\mathrm{I})}\right)$ dipoles can be calculated by the classical equations, and:

$$
\bar{w}_{C a(\mathrm{I})}-\bar{w}_{N a(\mathrm{I})}=-\bar{p}_{C a(\mathrm{I})} \bar{E}-\left(-\bar{p}_{N a(\mathrm{I})} \bar{E}\right)
$$

where $p_{i(\mathrm{I})}$ is the mean dipole moment of the $i$ th cation that results from classical induction theory. $\bar{E}$ is the mean electric field strength in the diffuse layer and $\bar{E}=\kappa \int_{0}^{1 / \kappa} E(x) d x=-\kappa\left[\varphi_{0}-\varphi(1 / \kappa)\right]$. The $\varphi_{0}$ values are from Table 1 , and the potential at $x=1 / \kappa \varphi(1 / \kappa)$ can also be obtained from the analytical solutions of the non-linear PoissonBoltzmann equation for the $1: 1$ and $2: 1$ electrolyte mixtures ${ }^{39}$.

The $\bar{p}_{i(\mathrm{I})}$ can be estimated from:

$$
\bar{p}_{i(\mathrm{I})}=4 \pi \varepsilon_{0} \varepsilon_{w} \alpha_{i}^{*} \bar{E}
$$

in which ${ }^{59} \alpha_{i}^{*}=\frac{3 V_{i}\left(\varepsilon_{i}-\varepsilon_{w}\right)}{4 \pi\left(\varepsilon_{i}+2 \varepsilon_{w}\right)}$ and $\varepsilon_{i}=1+\frac{4 \pi \alpha_{i}}{V_{i}}$.

where $\alpha_{i}{ }^{*}$ is the effective (excess) ionic polarizability in aqueous solution, $\varepsilon_{i}$ and $\varepsilon_{w}$ are the dielectric functions of the $i$ th ion species and water, respectively, $\varepsilon_{0}$ is the dielectric constant in vacuum, $V_{i}$ is the ionic volume, $\alpha_{i}$ is approximately equal to the intrinsic polarizability of the $i$ th ion species, $\alpha_{\mathrm{Ca}}=0.4692 \AA^{3}{ }^{60}$, and $\alpha_{\mathrm{Na}}=0.139 \AA^{359}$.

By substituting Eqs. 10 into Eq. 9, $\bar{w}_{\mathrm{Ca}(\mathrm{I})}-\bar{w}_{\mathrm{Na}(\mathrm{I})}$ can be calculated, and by substituting the result into Eq. $8, K_{\mathrm{C}+\mathrm{I}}$ can be calculated. The results plotted in Figure 3 indicate that the classical induction force could not explain the observed strong Hofmeister effects in $\mathrm{Ca}^{2+} \mathrm{Na}^{+}$ exchange. This is because the classical induction potential energies are very small relative to the Coulomb potential energies and can be completely neglected. Actually, the excess polarizabilities for $\mathrm{Ca}^{2+}$ and $\mathrm{Na}^{+}$are negative, which means that the classical induction forces between the surface and the cations are repulsive.

We have now shown that the strong Hofmeister effects in $\mathrm{Ca}^{2+}$ / $\mathrm{Na}^{+}$exchange did not derive from classic dispersion forces, induction forces, ionic sizes, or hydration effects. The London-Lifshiz

\begin{tabular}{|c|c|c|c|c|c|c|}
\hline$a_{\mathrm{Na}}$ & $a_{C a}$ & $a_{\mathrm{Na}} / a_{\mathrm{Ca}}$ & $\varphi_{0}(V)$ (new theory) & $\varphi_{1 / \kappa}(\mathrm{V})$ & $\beta_{C a}$ & $\beta_{\mathrm{Na}}$ \\
\hline 0.672 & 0.17 & 3.955 & -0.1153 & -0.02091 & 1.320 & 0.680 \\
\hline 0.956 & 0.167 & 5.724 & -0.1234 & -0.02215 & 1.235 & 0.765 \\
\hline 2.993 & 0.115 & 26.06 & -0.1206 & -0.02683 & 1.303 & 0.697 \\
\hline 4.697 & 0.144 & 32.63 & -0.1166 & -0.02724 & 1.323 & 0.677 \\
\hline 5.396 & 0.851 & 6.344 & -0.1000 & -0.0216 & 1.314 & 0.686 \\
\hline 7.893 & 1.361 & 5.800 & -0.1003 & -0.02137 & 1.250 & 0.750 \\
\hline 44.15 & 1.121 & 39.39 & -0.1025 & -0.02654 & 1.244 & 0.756 \\
\hline 60.35 & 0.061 & 990.5 & -0.1250 & -0.03241 & 1.316 & 0.684 \\
\hline 70.57 & 2.071 & 34.07 & -0.09563 & -0.02550 & 1.250 & 0.750 \\
\hline 25.1 & 8.729 & 2.875 & -0.08082 & -0.01853 & 1.256 & 0.744 \\
\hline 100.3 & 0.14 & 718.0 & -0.1199 & -0.03171 & 1.276 & 0.724 \\
\hline 120.5 & 0.2 & 603.6 & -0.1158 & -0.03114 & 1.281 & 0.719 \\
\hline
\end{tabular}

Table 2 | The calculated $\varphi_{0}, \varphi_{1 / \kappa}, \beta_{C a}$ and $\beta_{N a}$ values based on the experimental data

Activity $\left(\times 10^{3} \mathrm{~mol} / \mathrm{l}\right)$ 
theories on dispersion forces, induction forces, and hydration effects might be valid only when the external electric field is weak. In high electric fields $>4.2 \times 10^{8} \mathrm{~V} / \mathrm{m}$, however, it is possible that new interaction forces are present.

The general origin of Hofmeister effects at the interface. Because the differences between $K_{\mathrm{E}}$ and $K_{\mathrm{C}}$ sharply increase with surface potential, the unknown interaction force between the cations and the surface must be a function of the potential. Thus two parameters $\beta_{\mathrm{Ca}}$ and $\beta_{\mathrm{Na}}$ are introduced to modify the Coulomb interaction potential energies $\left(Z F \varphi_{0}\right)$ of $\mathrm{Ca}^{2+}$ and $\mathrm{Na}^{+}$. Eq. 4 can be changed to ${ }^{61}$ :

$$
K_{\text {modified }}=e^{-\frac{\left(\beta_{\mathrm{Ca}} Z_{\mathrm{Ca}}-\beta_{\mathrm{Na}} Z_{\mathrm{Na}}\right) \mathrm{F} \varphi_{0}}{2 R T}}
$$

Using the iteration approach suggested by Li et al. ${ }^{61}, \beta_{\mathrm{Ca}}, \beta_{\mathrm{Na}}$, and $\varphi_{0}$ can be calculated. If $\varphi_{0}$ is known, the potential at $x=1 / \kappa$ can also be calculated from the analytical solutions of the non-linear PoissonBoltzmann equation for $1: 1$ and $2: 1$ electrolyte solutions. The calculated values of $\varphi_{0}, \varphi(1 / \kappa), \beta_{\mathrm{Ca}}$ and $\beta_{\mathrm{Na}}$ are in Table 2 .

From Table 2, $\beta_{\mathrm{Ca}}>1$ and $\beta_{\mathrm{Na}}<1$, which implied that the unknown force for $\mathrm{Ca}^{2+}$ in cation-surface interactions was stronger than that for $\mathrm{Na}^{+}$. A comparison of surface potentials in Tables 1 and 2 also indicated that the unknown force decreased the surface potential significantly, perhaps because $\mathrm{Ca}^{2+}$ was more effective in screening than $\mathrm{Na}^{+}$

We used Table 2 to examine $\beta_{C a} v s . \varphi(1 / \kappa) / \varphi_{0}$ and $\beta_{N a} v s . \varphi(1 / \kappa) /$ $\varphi_{0}$. It was surprising that these were unusual linear relationships (with relative error $<0.3 \%$ ):

$$
\left\{\begin{array}{l}
\beta_{\mathrm{Ca}}=1+0.357-0.357 \frac{\varphi(1 / \kappa)}{\varphi_{0}} \\
\beta_{\mathrm{Na}}=1-0.357+0.357 \frac{\varphi(1 / \kappa)}{\varphi_{0}}
\end{array}\right.
$$

They were unusual because the slopes were equal to the "1-intercept" for the two cation species. If a new induction force in cation-surface interactions was introduced, Eqs. 12 could be theoretically derived. We tentatively refer to the new surface-potential-dependent force as a non-classic induction force, because it can be explained by the enhanced polarizability in strong external electric field from surface charges of illite particle.

An illite surface charge density of $0.2895 \mathrm{C} / \mathrm{m}^{2}$ corresponds to an electric field strength of $4 \pi \sigma_{0} / \varepsilon_{\text {water }}=4.2 \times 10^{8} \mathrm{~V} / \mathrm{m}\left(\varepsilon_{\text {water }}=8.9 \times\right.$ $\left.10^{-9} \mathrm{C}^{2} / \mathrm{J} \cdot \mathrm{m}\right)$ at the surface. The high external electric field may nonclassically and greatly enhance the dipole moments of the two cation species. The dipole moment of a cation species will be more strongly enhanced than others if it has a softer electron cloud and/or prefers to stay near surface of stronger electric field (e.g., a cation with a stronger electrostatic or dispersion force, and/or a chaotropic cation).

If the additional energies do come from the strong non-classic induction force, then:

$K_{\mathrm{C}+\mathrm{NI}}=e^{-\frac{\bar{w}_{C a(\mathrm{C})}-\bar{w}_{\mathrm{Na}}(\mathrm{C})+\bar{w}_{C a(\mathrm{NI})}-\bar{w}_{\mathrm{Na}(\mathrm{NI})}}{2 R T}}=e^{-\frac{\left(z_{\mathrm{Ca}}-Z_{\mathrm{Na}}\right) F \varphi_{0}+\bar{w}_{\mathrm{Ca}}(\mathrm{NI})-\bar{w}_{\mathrm{Na}(\mathrm{NI})}}{2 R T}}$

where $\bar{w}_{\mathrm{Ca}(\mathrm{NI})}$ and $\bar{w}_{\mathrm{Na}(\mathrm{NI})}$ are the strong non-classical induction energies $(\mathrm{J} / \mathrm{mol})$ in the adsorption phase of $\mathrm{Ca}^{2+}$ and $\mathrm{Na}^{+}$, respectively, which come from the strong polarization of the cations in the high electric field at the surface.

If the dipole orientation of the particle surface was co-directional and parallel with the high external electric field, the mean induction energies of $\mathrm{Ca}^{2+}$ and $\mathrm{Na}^{+}$dipoles in the field are:

$$
\left\{\begin{array}{l}
\bar{w}_{C a(\mathrm{NI})}=-\bar{p}_{\mathrm{Ca}(\mathrm{NI})} \bar{E}=\bar{p}_{\mathrm{Ca}(\mathrm{NI})} \kappa\left[\varphi_{0}-\varphi(1 / \kappa)\right] \\
\bar{w}_{\mathrm{Na}(\mathrm{NI})}=-\bar{p}_{\mathrm{Na}(\mathrm{NI})} \bar{E}=\bar{p}_{\mathrm{Na}(\mathrm{NI})} \kappa\left[\varphi_{0}-\varphi(1 / \kappa)\right]
\end{array}\right.
$$

where $\bar{p}_{\mathrm{Ca}(\mathrm{NI})}$ and $\bar{p}_{\mathrm{Na}(\mathrm{NI})}$ are the mean dipole moments $(\mathrm{dm} \cdot \mathrm{C} / \mathrm{mol})$ of $\mathrm{Ca}^{2+}$ and $\mathrm{Na}^{+}$in the diffuse layer, respectively.

Introducing Eq. 14 into Eq. 13:

$$
K_{\mathrm{C}+\mathrm{NI}}=e^{-\frac{\left.\left(Z_{\mathrm{Ca}}-Z_{\mathrm{Na}}\right) F \varphi_{0}+\bar{p}_{C a(\mathrm{NI})}{ }^{\kappa}\left[\varphi_{0}-\varphi(1 / \kappa)\right]-\bar{p}_{N a(\mathrm{NI})}\right)^{\kappa}\left[\varphi_{0}-\varphi(1 / \mathcal{L})\right]}{2 R T}}
$$

in which

$$
\begin{aligned}
& \left(Z_{\mathrm{Ca}}-Z_{\mathrm{Na}}\right) F \varphi_{0}+\bar{p}_{\mathrm{Ca}(\mathrm{NI})} \kappa\left[\varphi_{0}-\varphi(1 / \kappa)\right]-\bar{p}_{\mathrm{Na}(\mathrm{NI})} \kappa\left[\varphi_{0}-\varphi(1 / \kappa)\right] \\
& =Z_{\mathrm{Ca}} F \varphi_{0}-Z_{\mathrm{Na}} F \varphi_{0}+\frac{\left(Z_{\mathrm{Ca}}+Z_{\mathrm{Na}}\right)\left(\bar{p}_{\mathrm{Ca}(\mathrm{NI})}-\bar{p}_{\mathrm{Na}(\mathrm{NI})}\right) \kappa \varphi_{0}}{Z_{\mathrm{Ca}}+Z_{\mathrm{Na}}} \\
& -\frac{\left(Z_{\mathrm{Ca}}+Z_{\mathrm{Na}}\right)\left(\bar{p}_{\mathrm{Ca}(\mathrm{NI})}-\bar{p}_{\mathrm{Na}(\mathrm{NI})}\right) \kappa \varphi(1 / \kappa)}{Z_{\mathrm{Ca}}+Z_{\mathrm{Na}}} \\
& =\left[1+a \Delta \bar{p}_{(\mathrm{NI})}-a \Delta \bar{p}_{(\mathrm{NI})} \frac{\varphi(1 / \kappa)}{\varphi_{0}}\right] Z_{\mathrm{Ca}} F \varphi_{0} \\
& -\left[1-a \Delta \bar{p}_{(\mathrm{NI})}+a \Delta \bar{p}_{(\mathrm{NI})} \frac{\varphi(1 / \kappa)}{\varphi_{0}}\right] Z_{N a} F \varphi_{0}
\end{aligned}
$$

where $a$ is constant, and $a=\frac{1}{\left(Z_{\mathrm{Ca}}+Z_{\mathrm{Na}}\right)} \frac{\kappa}{F} ; \Delta \bar{p}_{(\mathrm{NI})}=\bar{p}_{\mathrm{Ca}(\mathrm{NI})}-\bar{p}_{\mathrm{Na}(\mathrm{NI})}$.

Substituting Eq. 16 into Eq. 15, one obtains:

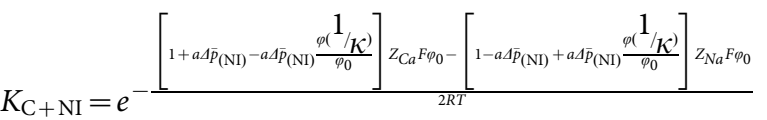

Comparing Eqs. 17 and 11, we have:

$$
\left\{\begin{array}{l}
\beta_{C a}=1+a \Delta \bar{p}_{(\mathrm{NI})}-a \Delta \bar{p}_{(\mathrm{NI})} \cdot \frac{\varphi(1 / \kappa)}{\varphi_{0}} \\
\beta_{\mathrm{Na}}=1-a \Delta \bar{p}_{(\mathrm{NI})}+a \Delta \bar{p}_{(\mathrm{NI})} \cdot \frac{\varphi(1 / \kappa)}{\varphi_{0}}
\end{array}\right.
$$

It is very interesting that the fitting equation Eq. 12 for the experimental data could be explained by the theoretical equation Eq. 18 . There are several reasons why this is very interesting. The expressions Eq. 18 are the same as Eq. 12 ; Eq. 18 verifies that $\beta_{\mathrm{Ca}}+\beta_{\mathrm{Na}}=2$; Eq. 18 verifies the "slope $=1$-intercept" in Eq. 12; and from Eqs. 18 and $12, a \Delta=0.357$.

By including the strong induction force, the relationship of $K_{\mathrm{C}+\mathrm{NI}}$ $\sim \varphi_{0}$ based on Eq. 17 (where $a \Delta \bar{p}_{(\mathrm{NI})}=0.357$ ) fitted the experimental data very well, as shown in Figure 4 . It is important to note that if we did not have the specific mathematical form of Eq. 18, the comparison with Eq. 12 could not have been done and the value of $a \bar{p} \Delta_{(\mathrm{NI})}=$

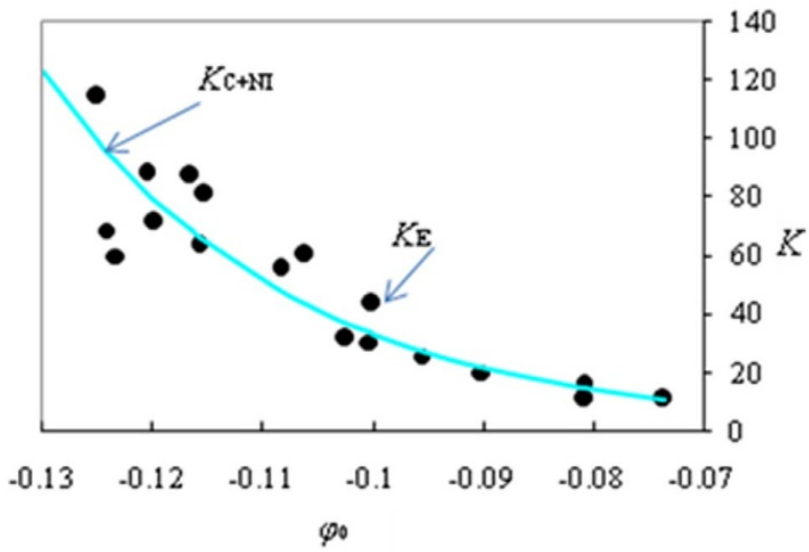

Figure $4 \mid$ Comparison between theoretical curves of $K_{\mathrm{C}+\mathrm{NI}}(-)$ and $K_{\mathrm{E}}$ $(\bullet)$. 
Table 3 | Comparison of mean potential energies of cations in diffusion layer producing from Coulomb force, classical induction and nonclassical forces respectively

Activity $\left(\times 10^{3} \mathrm{~mol} / \mathrm{l}\right)$

\begin{tabular}{|c|c|c|c|c|c|c|c|c|}
\hline$a_{\mathrm{Na}}$ & $a_{C a}$ & $\Delta \bar{w}_{(\mathrm{Cl})}(\mathrm{J} / \mathrm{mol})$ & $\Delta \overline{\mathrm{w}}_{(\mathrm{N})}(\mathrm{J} / \mathrm{mol})$ & $\Delta \bar{w}^{*}(\mathrm{II})(\mathrm{J} / \mathrm{mol})$ & $\Delta \overline{\mathrm{w}}_{(\mathrm{l})}(\mathrm{J} / \mathrm{mol})$ & $\Delta \bar{p}(\mathrm{NI})(D)$ & $\Delta \bar{p}^{*}{ }_{(\mathrm{I})}(D)$ & $\Delta \bar{p}_{(I)}(D)$ \\
\hline 0.672 & 0.17 & -11125 & -9754.0 & 0.054 & -0.387 & 448.6 & -0.0018 & 0.013 \\
\hline 0.956 & 0.167 & -11906 & -10463 & 0.062 & -0.440 & 416.3 & -0.0019 & 0.014 \\
\hline 2.993 & 0.115 & -11636 & -9690.0 & 0.162 & -1.160 & 300.5 & -0.0032 & 0.023 \\
\hline 4.697 & 0.144 & -11250 & -9234.2 & 0.239 & -1.712 & 244.0 & -0.0038 & 0.027 \\
\hline 5.396 & 0.851 & -9648.7 & -8101.7 & 0.257 & -1.839 & 179.7 & -0.0040 & 0.028 \\
\hline 7.893 & 1.361 & -9677.6 & -8156.4 & 0.295 & -2.108 & 145.5 & -0.0043 & 0.030 \\
\hline 44.15 & 1.121 & -9889.9 & -7849.5 & 1.053 & -7.539 & 80.34 & -0.008 & 0.058 \\
\hline 60.35 & 0.061 & -12061 & -9568 & 2.360 & -16.893 & 73.11 & -0.012 & 0.086 \\
\hline 70.57 & 2.071 & -9227.1 & -7247.1 & 1.950 & -13.954 & 62.90 & -0.011 & 0.078 \\
\hline 25.1 & 8.729 & -7798.1 & -6436.9 & 0.641 & -4.587 & 66.65 & -0.006 & 0.045 \\
\hline 100.3 & 0.14 & -11569 & -9113.3 & 2.860 & -20.469 & 56.61 & -0.013 & 0.095 \\
\hline 120.5 & 0.2 & -11173 & -8748.6 & 3.170 & -22.689 & 51.57 & -0.014 & 0.100 \\
\hline 161.8 & 0.235 & -11993 & -9517.4 & 4.970 & -35.575 & 44.60 & -0.017 & 0.125 \\
\hline
\end{tabular}

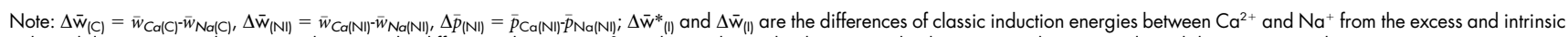
polarizabilities respectively, $\Delta \bar{p}^{*}\left(\right.$ (I) and $\Delta \bar{p}_{(I)}$ are the differences between $\mathrm{Ca}^{2+}$ and $\mathrm{Na}^{+}$classic dipole moments by the excess and intrinsic polarizabilities, respectively.

0.357 would not have been obtained. Therefore the $K_{\mathrm{C}+\mathrm{NI}} \sim \varphi_{0}$ relationship curve based on Eq. 17 is theoretical and not a fitting curve.

In summary, we have shown that a strong non-classic induction force of adsorbed ions in the electric field is the origin of the strong Hofmeister effects in $\mathrm{Ca}^{2+/} \mathrm{Na}^{+}$exchange.

Comparison of the strong non-classical and the classical induction energies. From $a \Delta \bar{p}_{(\mathrm{NI})}=0.357$, we have $\kappa \cdot \Delta \bar{p}_{(\mathrm{NI})}=0.357 \times 3 \times F$ $=103337 \mathrm{C}$ for $\mathrm{Ca}^{2+}$ and $\mathrm{Na}^{+}$. The differences in the non-classical induction energies between $\mathrm{Ca}^{2+}$ and $\mathrm{Na}^{+}$could be calculated from the $\mathrm{Ca}^{2+/} \mathrm{Na}^{+}$exchange experiments. From Eq. 14, we have:

$$
\begin{array}{r}
\bar{w}_{\mathrm{Ca}(\mathrm{NI})}-\bar{w}_{\mathrm{Na}(\mathrm{NI})}=\left(\bar{p}_{\mathrm{Ca}(\mathrm{NI})}-\bar{p}_{\mathrm{Na}(\mathrm{NI})}\right) \kappa\left[1-\frac{\varphi(1 / \kappa)}{\varphi_{0}}\right] \varphi_{0} \\
=3 a \Delta \bar{p}_{(\mathrm{NI})}\left[1-\frac{\varphi(1 / \kappa)}{\varphi_{0}}\right] F \varphi_{0} \\
=103337\left[\varphi_{0}-\varphi(1 / \kappa)\right]
\end{array}
$$

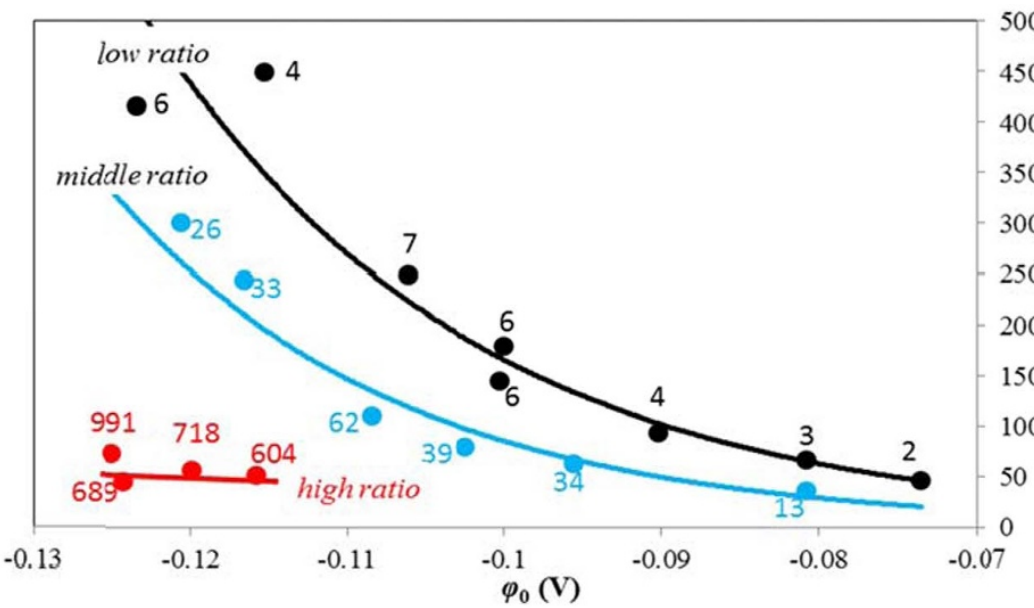

Figure $5 \mid \Delta \bar{p}_{(\mathrm{NI})}(\mathrm{D})$ vs. $\varphi_{0}(\mathrm{~V})$ under different $\mathbf{a}_{\mathrm{Na}}^{0} / \mathbf{a}^{0} \mathrm{Ca}$ ratios (numbers aside dots are the values of $\mathbf{a}^{0}{ }_{\mathrm{Na}} / \mathbf{a}^{0} \mathrm{Ca}$ ). with Eq. 19.
Thus the experimental values of $\bar{w}_{\mathrm{Ca}(\mathrm{NI})}-\bar{w}_{\mathrm{Na}(\mathrm{NI})}$ can be calculated

On the other hand, the surface-cation Coulomb force in such a high electric field would be much stronger than that for surface-water (surface hydration) and cation-water (cation hydration) interactions. As a result, the adsorbed cation near the surface might be to some degree dehydrated ${ }^{3}$ in the high electric field near the surface. In the extreme case of complete dehydration near the surface, we can use the intrinsic cation polarizability to calculate the dipole moment. Table 3 shows comparisons of $\Delta \bar{w}$ and $\Delta \bar{p}$ among the calculated results from cationic excess (Eqs. 9 and 10), the intrinsic polarizabilities and the observed non-classic results. There are several observations: (1) The observed non-classical induction energies $\Delta \bar{w}_{(\mathrm{NI})}$ are comparable with the Coulomb energies $\Delta \bar{w}_{(\mathrm{C})}$ in a wide range of electrolyte concentrations and ionic strengths over 0.00075$0.354 \mathrm{~mol} / \mathrm{l}$. (2) Even at very high electrolyte concentrations, the observed non-classic induction energies are large. (3) The classical induction energies (applying both excess and intrinsic polarizabilities) are so low relative to the observed high non-classic induction and Coulomb energies that they could be completely ignored. (4) 


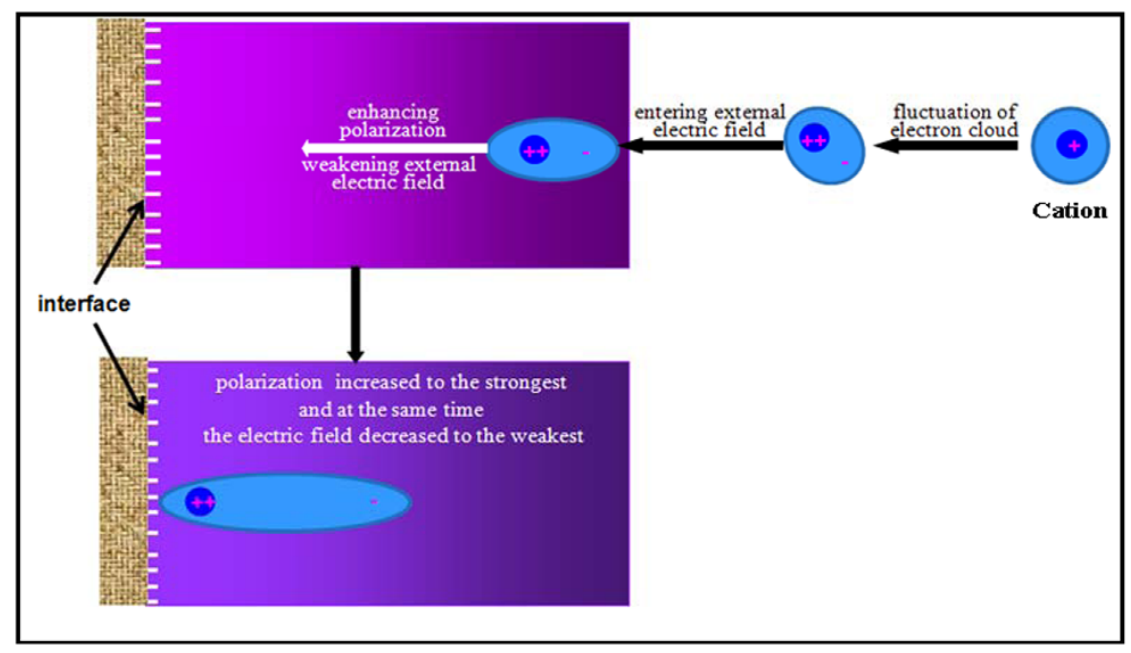

Figure 6 | The schematic diagram of a cation that is strongly polarized in an external electric field, and the field is weakened by the polarization.

From classical induction theories, $\Delta \bar{p}^{*}{ }_{(\mathrm{I})}$ or $\Delta \bar{p}_{(\mathrm{I})}$ decrease with an increase in external electric field (low electrolyte concentration corresponding to high external electric field); and this is not correct because in the classic theories we used constant ionic polarizabilities $\alpha_{i}^{*}$ and $\alpha_{i}$ in different electric fields.

The comparison of the observed large non-classical induction energy and the calculated classical induction energy indicated that in a strong external electric field of $10^{8}-10^{9} \mathrm{~V} / \mathrm{m}$, the ionic polarizabilities $\alpha_{i}^{*}$ and $\alpha_{i}$ would be heavily underestimated by the classical induction theories, and that they would sharply increase with electric field strength (Table 3). Therefore, a new theory to calculate ionic polarizability in strong electric fields is required; a successful theory for Hofmeister effects at solid/liquid interfaces should address the statistical mechanics of density fluctuations and their impact on solvent polarization ${ }^{36}$.

There are high electric fields $>10^{8}-10^{9} \mathrm{~V} / \mathrm{m}$ at the solid/liquid interfaces of clay, oxides, proteins, nanomaterials, and cell membranes. Therefore, the observed strong non-classical induction force will generally be the origin of Hofmeister effects at interface surfaces. In current treatments of Hofmeister effects, however, this important force has been ignored ${ }^{1,2}$; thus they may be correct only for weak electric fields.

It should be noted that the dielectric constant of water for bulk solution was used in all of the calculations. If it is actually lower near a surface relative to that in the bulk, then the $\Delta \bar{p}_{(\mathrm{NI})}$ values in Table 3 might be overestimated. Even if this was the case, it is unlikely to change the general conclusions of this study.

An extended analysis of the strong non-classic induction force. Table 3 had very large $\Delta \bar{p}_{(\mathrm{NI})}$ values, indicating that adsorbed ions in the electric field of the diffuse layer were strongly polarized. It also indicated that the polarization strength sharply increased with decreasing cation activity and that it was sensitive to the electric field strength in diffuse layer.

To demonstrate the effect of electric field strength in the diffuse layer on the polarization of adsorbed ions, we plotted $\Delta \bar{p}_{(\mathrm{NI})} v s . \varphi_{0}$ in Figure 5.

Even though $\Delta \bar{p}_{(\mathrm{NI})}$ generally increased with $\varphi_{0}$, there was appreciable scatter in Figure 5. However, if the data were divided into three groups according to $a_{\mathrm{Na}}^{0} / a^{0} \mathrm{Ca}$, the relationship of $\Delta \bar{p}_{(\mathrm{NI})} v s$. $\varphi_{0}$ became more transparent: low values of $a^{0}{ }_{\mathrm{Na}} / a^{0} \mathrm{Ca}$ over the range 1 -10 ; intermediate values over 10-100; and high values over $600-$ 1000 .

For low and intermediate values of $a_{\mathrm{Na}}^{0} / a^{0} \mathrm{Ca}$, we found that $\Delta \bar{p}_{(\mathrm{NI})}$ $=\bar{p}_{\mathrm{Ca}(\mathrm{NI})}-\bar{p}_{\mathrm{Na}(\mathrm{NI})}$ sharply increased with $\varphi_{0}$. Since the electronic structures for $\mathrm{Na}^{+}$and $\mathrm{Ca}^{2+}$ are, respectively, $1 \mathrm{~s}^{2} 2 \mathrm{~s}^{2} 2 \mathrm{p}^{6}$ (with a static polarizability $\alpha_{\mathrm{Na}}=0.139 \AA^{3}{ }^{59}$ ) and $1 \mathrm{~s}^{2} 2 \mathrm{~s}^{2} 2 \mathrm{p}^{6} 3 \mathrm{~s}^{2} 3 \mathrm{p}^{6}$ (with a static polarizability $\alpha_{\mathrm{Ca}}=0.4692 \AA^{3}{ }^{60}$ ), the electronic cloud for $\mathrm{Ca}^{2+}$ is "softer" than that for $\mathrm{Na}^{+}$. Therefore, quantum fluctuations for $\mathrm{Ca}^{2+}$ should be higher than those for $\mathrm{Na}^{+}$. The observation that $\Delta \bar{p}_{(\mathrm{NI})}=$ $\bar{p}_{\mathrm{Ca}(\mathrm{NI})}-\bar{p}_{\mathrm{Na}(\mathrm{NI})}$ sharply increased with $\varphi_{0}$ indicated that the difference in random quantum fluctuation between $\mathrm{Ca}^{2+}$ and $\mathrm{Na}^{+}$was strongly and directionally enhanced by the high external electric field.

At a constant surface potential $\varphi_{0}$ (e.g., $\left.-0.12 \mathrm{~V}\right), \Delta \bar{p}_{(\mathrm{NI})}=$ $\bar{p}_{\mathrm{Ca}(\mathrm{NI})}-\bar{p}_{\mathrm{Na}(\mathrm{NI})}$ sharply decreased with increased $a_{\mathrm{Na}}^{0} / a^{0} \mathrm{Ca}$. A larger $a^{0}{ }_{\mathrm{Na}} / a^{0} \mathrm{Ca}$ means more $\mathrm{Na}^{+}$could be distributed in the inner space of diffuse layer. The electric field was higher in the inner diffuse layer; thus, for larger $a_{\mathrm{Na}}^{0} / a^{0} \mathrm{Ca}$, more $\mathrm{Na}^{+}$might have random quantum fluctuations directionally enhanced. As a result, $\Delta \bar{p}_{(\mathrm{NI})}=\bar{p}_{\mathrm{Ca}(\mathrm{NI})^{-}}$ $\bar{p}_{\mathrm{Na}(\mathrm{NI})}$ decreased.

Even with very high $a_{\mathrm{Na}}^{0} / a_{\mathrm{Ca}}^{0}$ ratios (e.g., 604-991), $\Delta \bar{p}_{(\mathrm{NI})}=$ $\bar{p}_{\mathrm{Ca}(\mathrm{NI})}-\bar{p}_{\mathrm{Na}(\mathrm{NI})}>0$, which implies a strong preference of the surface for $\mathrm{Ca}^{2+}$ over $\mathrm{Na}^{+}$. Three key factors will influence that preference: cation charge number (Coulomb force), cation flexibility (dispersion force), and hydration (chaotropic or kosmotropic ${ }^{1,2}$ ). Even though $\mathrm{Ca}^{2+}$ is kosmotropic and $\mathrm{Na}^{+}$is chaotropic, the charge number and flexibility of $\mathrm{Ca}^{2+}$ are higher than that of $\mathrm{Na}^{+}$, so the surface prefers $\mathrm{Ca}^{2+}$ over $\mathrm{Na}^{+}$. Therefore, Coulomb forces, dispersion forces, and hydration effects appeared to be interwined to influence cation distribution at the interface. In Levin theory, only hydration determines that preference ${ }^{1,2}$.

The difference in quantum fluctuations between $\mathrm{Ca}^{2+}$ and $\mathrm{Na}^{+}$ could be strongly and directionally enhanced by the high external electric field that created enormous values of $\bar{p}_{\mathrm{Ca}(\mathrm{NI})}-\bar{p}_{\mathrm{Na}(\mathrm{NI})}=$ $\Delta \bar{p}_{(\mathrm{NI})}$. The complex combination of Coulomb, dispersion and hydration effects would also greatly affect the enhancement. In addition, the enhancement would decrease the external electric field because the additional strong non-classical induction force significantly concentrated the counter-ions in the near-surface region.

Similar to London-Lifshiz forces, quantum fluctuations might be the essential origin of the new force. However, unlike London-Lifshiz forces, the random quantum fluctuations might be strongly and directionally enhanced by the high external electric field. Therefore if the quantum fluctuation was the essential cause of the new force, the high electric field would be its external cause. Here, we tentatively refer to this new force as a non-classical induction force, but the induction concept could not exactly describe it. Therefore, we suggest that the new force might derive from the coupling of ionic quantum fluctuations and the high external electric field. The classic Coulomb forces, dispersion forces, ionic size, and hydration effects combine to determine the preference for ion to stay at a surface over others, thus affecting the coupling effect. This concept is schematic- 
ally illustrated in Figure 6. We emphasize we are simply illustrating a possible explanation of the new force; a complete description about the nature of the new force is still required.

\section{Conclusions}

We have observed a strong non-classical induction force in cationsurface interactions. Hofmeister effects in general may derive from this force, and the results presented here may fundamentally challenge all related theories. Currently, it is believed that DerjaguinLandau-Verwey-Overbeek theory and the double-layer theory are exact at low electrolyte concentrations; and at high concentrations, dispersion forces, ionic sizes and hydration effects must be taken into account for the explanation of Hofmeister effects. In contrast, our results indicate that the most important forces are not those classic interactions. Instead, they are the strong non-classical induction forces at high and especially at low concentrations for the explanation of Hofmeister effects. The classic Coulomb forces, dispersion forces, ionic size, and hydration effects appeared to be interwined in determining the preference for an ion species to stay at a surface over others, thus affecting the strong non-classical induction forces.

The strong non-classical induction force implies that the energies of non-valence electrons of ion species at the interface might be substantially understated, and that they may profoundly influence the physical and chemical properties of ions, atoms, and molecules. Therefore, to describe Hofmeister effects occurring at interfaces with high electric fields, a combined solution of Schrodinger's equation and the Poisson-Boltzmann equation would be required, and that the energy produced by the field near the interface should be exactly included in the Hamilton operator.

1. Santos, A. P. d. \& Levin, Y. Ion Specificity and the Theory of Stability of Colloidal Suspensions. Phys. Rev. Lett. 106, 167801 (2011).

2. Levin, Y., Santos, A. P. d. \& Diehl, A. Ions at the Air-Water Interface: An End to a Hundred-Year-Old Mystery? Phys. Rev. Lett. 103, 257802 (2009).

3. Parsons, D. F., Boström, M., Nostro, P. L. \& Ninham, B. W. Hofmeister effects: interplay of hydration, nonelectrostatic potentials, and ion size. Phys. Chem. Chem. Phys. 13, 12352-12367 (2011).

4. Gurau, M. C. et al. On the mechanism of the Hofmeister effect. J. Am. Chem. Soc. 126, 10522-10523 (2004).

5. Kunz, W., Henle, J. \& Ninham, B. 'Zur Lehre von der Wirkung der Salze'(about the science of the effect of salts): Franz Hofmeister's historical papers. Curr. Opin. Colloid Interface Sci. 9, 19-37 (2004).

6. Kunz, W., Lo Nostro, P. \& Ninham, B. The present state of affairs with Hofmeister effects. Curr. Opin. Colloid Interface Sci. 9, 1-18 (2004).

7. Petrache, H. I., Zemb, T., Belloni, L. \& Parsegian, V. A. Salt screening and specific ion adsorption determine neutral-lipid membrane interactions. Proc. Natl. Acad. Sci. USA 103, 7982-7987 (2006).

8. Boström, M., Williams, D. R. M. \& Ninham, B. W. Specific Ion Effects: Why DLVO Theory Fails for Biology and Colloid Systems. Phys. Rev. Lett. 87, 168103 (2001).

9. Ninham, B. W. Physical chemistry: The loss of certainty. Prog. Colloid Polym. Sci. 120, 1-12 (2002).

10. Nostro, P. L. et al. Specific ion effects on the growth rates of Staphylococcus aureus and Pseudomonas aeruginosa. Phys. Bio. 2, 1-7 (2005).

11. Jungwirth, P. \& Tobias, D. J. Specific Ion Effects at the Air/Water Interface. Chem. Rev. 106, 1259-1281 (2006).

12. Chen, X., Yang, T., Kataoka, S. \& Cremer, P. S. Specific ion effects on interfacial water structure near macromolecules. J. Am. Chem. Soc. 129, 12272-12279 (2007)

13. Tobias, D. J. \& Hemminger, J. C. Getting specific about specific ion effects. Science 319, 1197-1198 (2008).

14. Fedorov, M. V., Goodman, J. M. \& Schumm, S. To switch or not to switch: the effects of potassium and sodium ions on $\alpha$-poly-l-glutamate conformations in aqueous solutions. J. Am. Chem. Soc. 131, 10854-10856 (2009).

15. Hallberg, F., Furo, I. \& Stilbs, P. Ion Pairing in Ethanol/Water Solution Probed by Electrophoretic and Diffusion NMR. J. Am. Chem. Soc. 131, 13900-13901 (2009).

16. Zhang, Y. \& Cremer, P. S. The inverse and direct Hofmeister series for lysozyme. Proc. Natl. Acad. Sci. U.S.A. 106, 15249-15253 (2009).

17. Lo Nostro, P., Peruzzi, N., Severi, M., Ninham, B. W. \& Baglioni, P. Asymmetric Partitioning of Anions in Lysozyme Dispersions. J. Am. Chem. Soc. 132, 6571-6577 (2010).

18. Zhang, Y. \& Cremer, P. S. Chemistry of Hofmeister anions and osmolytes. Annu. Rev. Phys. Chem. 61, 63-83 (2010).
19. Funkner, S. et al. Watching the low frequency motions in aqueous salt solutions--the terahertz vibrational signatures of hydrated ions. J. Am. Chem. Soc. 134, 1030-1035 (2012).

20. Boroudjerdi, H. et al. Statics and dynamics of strongly charged soft matter. Phys Rep. 416, 129-199 (2005).

21. Bolt, G. H. Ion Adsorption by Clays. Soil Sci. 79, 267-276 (1955).

22. Mullet, M., Fievet, P., Reggiani, J. C. \& Pagetti, J. Surface electrochemical properties of mixed oxide ceramic membranes: Zeta-potential and surface charge density. J. Membr. Sci. 123, 255-265 (1997).

23. Mao, M., Fornasiero, D., Ralston, J., Smart, R. S. C. \& Sobieraj, S. Electrochemistry of the zircon-water interface. Colloids Surf. A 85, 37-49 (1994).

24. Bowen, W. R. \& Mukhtar, H. Properties of microfiltration membranes: the surface electrochemistry of mixed oxide ceramic membranes. Colloids Surf. A 81, 93-101 (1993).

25. Smit, W. \& Holten, C. L. M. Zeta-potential and radiotracer adsorption measurements on EFG $\alpha-\mathrm{Al}_{2} \mathrm{O}_{3}$ single crystals in $\mathrm{NaBr}$ solutions. J. Colloid Interface Sci. 78, 1-14 (1980).

26. Liu, X., Li, H., Li, R., Tian, R. \& Xu, C. Combined determination of surface properties of nanocolloidal particles through ion selective electrodes with potentiometer. Analyst 138, 1122-1129 (2013).

27. Zhang, Z. Z., Sparks, D. L. \& Scrivner, N. C. Characterization and Modeling of the Al-Oxide/Aqueous Solution Interface: I. Measurement of Electrostatic Potential at the Origin of the Diffuse Layer Using Negative Adsorption of $\mathrm{Na}^{+}$Ions $J$. Colloid Interface Sci. 162, 244-251 (1994).

28. Missana, T. \& Adell, A. On the Applicability of DLVO Theory to the Prediction of Clay Colloids Stability. J. Colloid Interface Sci. 230, 150-156 (2000).

29. Li, H., Wei, S., Qing, C. \& Yang, J. Discussion on the position of the shear plane. J. Colloid Interface Sci. 258, 40-44 (2003).

30. Pashley, R. M. DLVO and Hydration Forces between Mica Surfaces in $\mathrm{Li}^{+}, \mathrm{Na}^{+}$, $\mathrm{K}^{+}$, and $\mathrm{Cs}^{+}$Electrolyte Solutions: A Correlation of Double-Layer and Hydration Forces with Surface Cation Exchange Properties. J. Colloid Interface Sci. 83, 531-546 (1981).

31. Leng, Y. Hydration Force between Mica Surfaces in Aqueous KCl Electrolyte Solution. Langmuir 28, 5339-5349 (2012).

32. Ducker, W. \& Pashley, R. Forces between mica surfaces in the presence of rodshaped divalent counterions. Langmuir 8, 109-112 (1992).

33. Barber, J. Membrane surface charges and potentials in relation to photosynthesis Biochim. Biophys. Acta Bioenerg. 594, 253-308 (1980).

34. Kinraide, T. B. \& Wang, P. The surface charge density of plant cell membranes $(\sigma)$ : an attempt to resolve conflicting values for intrinsic $\sigma$. J. Exp. Bot. 61, 2507-2518 (2010).

35. Dobrzynska, I., Skrzydlewska, E. \& Figaszewski, Z. Parameters characterizing acid-base equilibria between cell membrane and solution and their application to monitoring the effect of various factors on the membrane. Bioelectrochem. 69 , 142-147 (2006).

36. Noah-Vanhoucke, J. \& Geissler, P. L. On the fluctuations that drive small ions toward, and away from, interfaces between polar liquids and their vapors. Proc. Natl. Acad. Sci. U.S.A. 106, 15125-15130 (2009).

37. Manning, G. S. Limiting laws and counterion condensation in polyelectrolyte solutions. 7. Electrophoretic mobility and conductance. J. Phys. Chem. 85, 1506-1515 (1981).

38. Stellwagen, E. \& Stellwagen, N. C. Probing the electrostatic shielding of DNA with capillary electrophoresis. Biophys. J. 84, 1855-1866 (2003).

39. Liu, X., Li, H., Li, R. \& Tian, R. Analytical Solutions of the Nonlinear PoissonBoltzmann Equation in Mixture of Electrolytes. Surf. Sci. 607, 197-202 (2013).

40. Liu, X. et al. Hofmeister effects on cation exchange equilibrium: quantification of ion exchange selectivity. J. Phys. Chem. C 117, 6245-6251 (2013).

41. Kiriukhin, M. Y. \& Collins, K. D. Dynamic hydration numbers for biologically important ions. Biophys. Chem. 99, 155-168 (2002).

42. Liu, X., Li, H., Li, R., Tian, R. \& Xu, C. Generalized Poisson-Boltzmann Equation Taking into Account Ionic Interaction and Steric Effects. Commun. Theor. Phys. 58, 437-440 (2012)

43. Moreira, L. A., Boström, M., Ninham, B. W., Biscaia, E. C. \& Tavares, F. W. Hofmeister effects: Why protein charge, $\mathrm{pH}$ titration and protein precipitation depend on the choice of background salt solution. Colloids Surf. A 282-283, 457-463 (2006).

44. López-León, T., Santander-Ortega, M. J., Ortega-Vinuesa, J. L. \& BastosGonzález, D. Hofmeister effects in colloidal systems: influence of the surface nature. J. Phys. Chem. C 112, 16060-16069 (2008).

45. Kunz, W. Specific ion effects in colloidal and biological systems. Curr. Opin. Colloid Interface Sci. 15, 34-39 (2010).

46. Boström, M., Williams, D. R. M. \& Ninham, B. W. Surface tension of electrolytes: specific ion effects explained by dispersion forces. Langmuir 17, 4475-4478 (2001).

47. Kim, H. K., Tuite, E., Nordén, B. \& Ninham, B. Co-ion dependence of DNA nuclease activity suggests hydrophobic cavitation as a potential source of activation energy. Eur. Phys. J. E 4, 411-417 (2001).

48. Nakao, H., Nagaoka, T. \& Ogura, K. Ion-Exchange Ability of PolyanilinePolyvinyl Alcohol Colloids with Various Anions. Anal. Sci. 13, 327-331 (1997)

49. Sodaye, S., Suresh, G., Pandey, A. K. \& Goswami, A. Determination and theoretical evaluation of selectivity coefficients of monovalent anions in anionexchange polymer inclusion membrane. J. Membr. Sci. 295, 108-113 (2007). 
50. Teppen, B. J. \& Miller, D. M. Hydration energy determines isovalent cation exchange selectivity by clay minerals. Soil Sci. Soc. Am. J. 70, 31-40 (2006).

51. Liu, X., Li, H., Li, R., Tian, R. \& Hou, J. A new model for cation exchange equilibrium considering the electrostatic field of charged particles. J. Soils Sed. 12, 1019-1029 (2012).

52. Samanta, S. \& Misra, B. Ion exchange selectivity of a resorcinol-fqrmaldehyde polycondensate resin for cesium in relation to other alkali metal ions. Solvent Extr. Ion Exch. 13, 575-589 (1995).

53. Laird, D. A. \& Shang, C. Relationship between cation exchange selectivity and crystalline swelling in expanding 2:1 phyllosilicates. Clays Clay Miner 45 , 681-689 (1997).

54. Eberl, D. D. Alkali cation selectivity and fixation by clay minerals. Clays Clay Miner 28, 161-172 (1980).

55. Pauley, J. L. Prediction of cation-exchange equilibria. J. Am. Chem. Soc. 76 1422-1425 (1953)

56. Shainberg, I. \& Kemper, W. D. Hydration status of adsorbed cations. Soil Sci. Soc. Am. Proc. 30, 707-713 (1966).

57. Borukhov, I., Andelman, D. \& Orland, H. Steric Effects in Electrolytes: A Modified Poisson-Boltzmann Equation. Phys. Rev. Lett. 79, 435-438 (1997).

58. Lou, P. \& Lee, J. Y. Ionic Size Effect on the Double Layer Properties: A Modified Poisson-Boltzmann Theory. Bull. Korean Chem. Soc 31, 2553-2556 (2010).

59. Parsons, D. F. \& Ninham, B. W. Importance of accurate dynamic polarizabilities for the ionic dispersion interactions of alkali halides. Langmuir 26, 1816-1823 (2010).

60. Parsons, D. F. \& Ninham, B. W. Charge reversal of surfaces in divalent electrolytes: the role of ionic dispersion interactions. Langmuir 26, 6430-6436 (2010).

61. Li, H., Hou, J., Liu, X. \& Wu, L. Combined Determination of Specific Surface Area and Surface Charge Properties of Charged Particles from a Single Experiment. Soil Sci. Soc. Am. J. 75, 2128-2135 (2011).

\section{Acknowledgments}

This work was supported by the National Natural Science Foundation of China (Grant No. 41371249 and 41101223), Natural Science Foundation Project of CQ CSTC (Grant No. CSTC, 2011BA7001) and 973 Program (Grant No. 2010CB134511).

\section{Author contributions}

X.L. and H.L. performed the data analysis and modeling, and wrote the main manuscript text. R.L. prepared Table 1-3. J.N. and D.X. supervised the project. L.W. made a thoroughgoing revision of the manuscript. X.L. and H.L. contributed equally to this work. All authors reviewed the manuscript.

\section{Additional information}

Competing financial interests: The authors declare no competing financial interests.

How to cite this article: Liu, X.M. et al. Strong non-classical induction forces in ion-surface interactions: General origin of Hofmeister effects. Sci. Rep. 4, 5047; DOI:10.1038/srep05047 (2014)

This work is licensed under a Creative Commons Attribution-NonCommercialNoDerivs 3.0 Unported License. The images in this article are included in the article's Creative Commons license, unless indicated otherwise in the image credit; if the image is not included under the Creative Commons license, users will need to obtain permission from the license holder in order to reproduce the image. To view a copy of this license, visit http://creativecommons.org/licenses/by-nc-nd/3.0/ 